\title{
Education in Biosphere Reserves to Enhance Intercultural Competence between Japanese and Russian Youth
}

\author{
Aida Mammadova ${ }^{1}$
}

\begin{abstract}
Japan and Russian youth has many stereotypical cultural perceptions about each other's culture, which in many times leads to cultural misunderstandings with negative effects. In this study we decided to use Biosphere Reserves (BRs), which are highly recognized areas under UNESCO's MAB Programme for their conservation, learning and sustainable development initiatives, to enhance the cultural competence and awareness in youth of both countries. 50 Japanese students were divided into two groups and visited 3 Russian BR with 4 universities, with 2 weeks' duration of each trip. Later 14 Russian students visited Japanese Mount Hakusan BR and participated in the academic BR training course for 3-weeks. We have conducted the specific survey to evaluate the changes in students' knowledge, attitude and skills towards each other's culture, and it was observed that all 3 elements were increased in all students. Besides $90 \%$ of students replied that they were strongly agree, that BR helped them to understand cultural diversity of each county. $87 \%$ replied that community interaction was the most effective way to break cultural stereotypes. This kind of crosscultural communication in BR, showed very positive results and can be used as the new methodology for the future environmental education.
\end{abstract}

Keywords: Environmental Education, Sustainability, Biosphere Reserves, Cultural Competence, Awareness

\section{Introduction}

Learning from other cultures is essential and important for the students to connect with different concepts and ideas on values, believes and the culture specific ways of living in the globalizing world. Internalization is considered as a critical aspect of education and cultural education plays significant part to teach the youth how to adapt and relate with the diverse cultural environment. Educational programs abroad prepare students to be more intercultural competent, and enhance the intercultural communication skills. The only judgement is that most of the programs provides the courses with the focuses on culture alone. Some researches argue, that education abroad with only culture alone, may increase the cognitive and behavior skills, but would not develop the deeper levels of intercultural competence (Root \& Ngampornchai, 2013).

Intercultural competence is the term applied to the "ability to develop targeted knowledge, skills and attitudes that lead to visible behavior and communication that are both effective and appropriate in intercultural interactions" (Deardorff, 2006). Awareness, knowledge and skills towards the different culture are the three main elements of intercultural competence (Sue \& Sue 2012), which lead to the effective and appropriate communication with people of different cultures. Lack of those competencies and the inability to understand the different culture can lead to the cultural encapsulation (Roysircar \& Gilla, 2010) or to create the stereotypical perception of culture (Krueger, 1996). 
It is known that cultural diversity is derived from the surrounded natural environment according to the biological diversities of the specific regions (Maffi \& Woodley, 2012). Considering the interdependence of cultural and biological aspects, during educational cultural programs it is important to show the interlinkage of biological diversity as well. In this study we have suggested that by introducing the biological diversity into the cultural oriented programs, will increase the intercultural competence. For our purpose, we chose Biosphere Reserves (BRs) as the fields of our study, and decided to investigate how the cross-cultural fieldtrips will increase the intercultural competences in youth.

The UNESCO's Man and Biosphere (MAB) Programme was launched in 1971, to better understand the biological, cultural and socioeconomic factors that affects the environment and the involvement of the scientist and decision-makers for the future sustainable management of the natural resources (Von Droste, 1991). MAB program has designated the areas with the significant conservational importance in the world as the Biosphere Reserves (BRs). BRs considered as the model regions for the sustainable development, whose inhabitants pursue environmental livelihoods and support the development of the sustainable societies and economies of the regions (Batisse, 1980). Function as the model for sustainable development BRs provide the learning site for the successful implementation of the UN's 2030 Agenda (MAB STRATEGY, 2015). BRs functioning as the educational side (Ishwaran et al., 2008), can provide the learning platform at the local and international levels, by implementing the specific training programs towards the cultural competences. However, how well BRs can be effective to increase intercultural cultural competence in youth, is still unknown. We decided to create the educational programs for Russian and Japan students to evaluate the intercultural competence through learning of each other culture and nature inside the BRs.

Russian west part is territorially close to Japanese archipelago, but both countries has very different cultural origin and perception of each other's countries culture most of the type is based on some stereotypes or prejudices. Russia is multicultural and multiethnic country which is inhabited by more than 186 ethnic groups, where as Japan is the most homogenous population in the world. In spite that Russian has the diverse nationalities and diverse cultures, Japanese perception of their culture is mostly based on common stereotypical misconceptions, that Russian people are hard drinking nation, they all grumpy and racist, the county is extremely cold and bears roam in the streets etc. It is very hard for Japanese to realize that Mongolian, Turkic, Caucasian and many other ethnic groups with diverse culture are also live inside the Russian. In reverse, Japan for century was closed county and considered as the most monocultural and insulated country in the world. For many years had the strong immigration policies controlling the number of foreigners. Only after 1980 with the change of immigration policies (Tezuka, 2005), Japan was recognized as the multicultural and multi-national country. However, even now many discriminations are felt towards foreigners, due to the cultural miscommunications and misunderstandings.

\section{Methods and Results}

Educational program was divided into the two parts: Russia Outbound and Japan Inbound training courses. Outbound programs were divided into two parts: West 
Russia and East Russia courses, by sending 25 Japanese students in each course for two weeks. In total, during outbound course 50 Japanese students visited four Russian universities (Kazan Federal University, Altai State University, Irkutsk State University and Far East Federal University) and three main Russian BRs (Volzhsko-kamsky BR, Baykalskiy BR and Far East Marine BR), several National Parks (Land of the Leopard in the Primorskiy Krai, Down Kama in the Republic of Tatarstan) and one Nature Park Belokurikha in Altai Krai.

During the Japan Inbound course, 14 Russian students from Kazan Federal University, Altai State University, Irkutsk State University and Far East Federal University visited Japan, and spend three weeks in the remote village of Mount Hakusan BR.

To conduct the both Outbound and Inbound courses the working group was created in each country with diverse members, including the academic researchers, local authorities, NPOs, members of MAB or BR committees, private industries, individual entrepreneurs and local people.

At the beginning of each courses the professional instructors gave basic explanation about the region, concerning the landscapes, ecological and social-economic backgrounds of the region, and explained the local issues related with the socialeconomic and environmental changings. Later students had the experiential practice together with the local communities inside the BRs. All trips were guided by the professional local instructors and educators, and were issue-oriented.

Both courses were divided into the following thematic trips; 1. Biological and cultural diversity of each country and its relation with human livelihoods, 2. Relation between Biosphere Reserve, Geoparks, Natural Parks, Resorts and World Heritage sites and how those sides are connected to preserve the traditional cultural values 3. Searching the link between nature preservation and local enterprises

Objectives of the course were as below:

- to understand the diverse cultural and natural differences of each country

- increase the communication, creativity and decision making skills between Russian and Japanese students during BR's natural activities

- learn about Human-Nature-Culture Interaction and use that knowledge for the regional revitalization of each country

\subsection{Data Collection}

Data collection was carried out to evaluate the intercultural competence elements like attitudes/awareness, knowledge and skills on culture of each country. Each element had several specifically designed questions with factor analysis. Knowledge and skills elements were scored by $1=$ Very Bad, 2=Bad, 3=Good, 4=Very Good and multiple-choice questions. Attitudes/awareness were employed by Likert scale of four rates $1=$ Strongly Disagree, 2=Disagree, 3=Agree and $4=$ Strongly Disagree, and concerns were rates as $1=$ Not concerned at all, $2=$ Somewhat concerned, $3=$ Neutral, 4 = Concerned, $5=$ Very concerned. After courses, closed-ended questions and multiple-choice question were collected, with yes/no replies, to evaluate the changes. All students were required to submit the reports after the completion of the course. 


\subsection{Results}

It was observed that all 3 elements of intercultural competences (attitude/awareness, knowledge and skills) were increased in students. After the completion of the course, in Russia outbound with $n=50$, attitude/awareness was $92 \%$, knowledge $76 \%$ and skills $96 \%$. For Japan inbound with $\mathrm{n}=14$, attitude/awareness was $92 \%$, knowledge $85 \%$ and skills $64 \%$. Also, $64 \%$ of Japanese students replied that the perception of the Russian culture was changed. Besides $90 \%$ of students from total 64 students replied that they were strongly agree, that BR helped them to understand cultural diversity of each county. $87 \%$ from total 64 students replied that community interaction was the most effective way to break cultural stereotypes. Most of the students $(n=55)$ replied that BR increased the ability to analyses the current situation and acceptance of different culture with different language.

\section{Discussions}

This study showed that using BRs as the fieldtrips for international programs can increase the intercultural competence in youth. Especially, in both Outbound and Inbound courses, it was notice that by introducing the biological factors into the culture oriented practices helped to deepen the levels of intercultural competence, and 90\% of students expressed that BRs with community interaction programs helped them to deeply realize about the cultural diversity of each country. The results indicated the ability to accept cultural differences and recognize the importance of diverse values and believes, which are the key factors in the development of the intercultural competence (Bennet, 1993).

Most of Japanese students replied that their attitude towards the Russian culture changed into positive way "...nature activities transformed the stereotypical image about Russia and seeing the coexistence of different religions and ethnic groups was the most impressive to understand the diversity of Russian people". Awareness and the skills were clearly increased in Japanese students, with the ability to analyze and related the certain parts of Russian people's behavior with diverse ethnicity and living conditions. For many years' Japanese people were skeptical towards the foreigners and had the "foreigncomplex" (Kowner, 2002; Haugh, 2003), and this complex was not only related with the linguistic barriers, but with non-verbal behavior of foreigners (Mammadova, 2019), which in many cases were interpreted as "rude behavior". Community interaction inside the BRs, helped to develop the skills and knowledge which were culture specific and also increased the ability to analyze and explain the origin of the certain behavior. It was accepted that what is considered to be rude in Japanese culture, is not rude in Russian.

For Russian students who spend three weeks inside the remote village of Mount Hakusan BR, awareness and knowledge towards the Japanese culture were mainly increased. Stated by the student "...culture inside the village was so different from those that we used to hear about Japan, as the technologically advanced country with super modernized and robotized environment. In the village, we saw complete different. Local villagers still were preserving the traditional way of living and were very much similar to Russian old people. We learned how to respect their values and learned lots of background knowledge about the origin of their lifestyle". Russian students 
demonstrated the combination of their limited awareness component with the willingness to seek information and knowledge of unknown culture, which are important components of intercultural competences (Spitzberg \& Chagnon, 2009).

This kind of cross-cultural communication inside BR, showed very positive results toward the intercultural competences. BRs, can be used as the platforms to link cultural and biological diversity, and can be helpful to develop new educational methodologies not only for the culture oriented programs, but also in the environmental education. In future, it will be important to observe how those competencies which were gained during the training programs, influenced the chance to be employed in the various organizations with global missions.

\section{Conclusion}

In this study, we have conducted cross-cultural Inbound course to Japan for 14 Russian and Outbound course to Russian for 50 Japanese students, by using the Biosphere Reserves as the platform to increase the intercultural competencies. it was shown that BRs can increase the intercultural competence in youth, by introducing the biological factors into the culture oriented practices. Particularly, community interaction programs inside BRs helped them to deeply realize about the cultural diversity of each country. All three elements of the cultural competences (attitude/awareness, skills and knowledge) were increase in both Outbound and Inbound courses. In future studies, we are going to evaluate how those acquired intercultural skills contributed in their future employment.

\section{References}

Batisse M. (1980). The Relevance of MAB. Environmental Conservation, 7(3), pp. 179-84

Bennett, M.J. (1993). Towards ethnocentrism: A developmental model of intercultural sensitivity. In R.M. Paige (Ed.), Education for the Intercultural Experience (pp. 21-71). Yarmouth, ME: Intercultural Press.

Deardorff, D. K. (2006). The Identification and Assessment of Intercultural Competence as a Student Outcome of Internationalization at Institutions of Higher Education in the United States, Journal of Studies in International Education 10:241-266

Haugh, M. (2003). Japanese and Non-Japanese Perception of Japanese Communication. New Zealand Journal of Asian Studies, 5, 156-177.

Ishwaran, N., Persic, A., \& Tri, N. H. (2008). Concept and practice: the case of UNESCO biosphere reserves. International Journal of Environment and Sustainable Development, 7(2), 118-131.

Kowner, R. (2002). Japanese communication in intercultural encounters: The barrier of status-related behavior. International journal of intercultural relations, 26(4), 339-361.

Krueger, J. (1996). Personal beliefs and cultural stereotypes about racial characteristics. Journal of personality and Social Psychology, 71(3), 536.

MAB STRATEGY 2015-20252, Retrieved from, http://www.unesco.org/fileadmin/MULTIMEDIA/HQ /SC/pdf/Final_Draft_MAB_Strategy_4-5-15_en.pdf, March 2019

Maffi, L., \& Woodley, E. (2012). Biocultural diversity conservation: a global sourcebook. Routledge.

Mammadova, A. (2019) Cross-Cultural Homestay and Challenges to Accept Foreign Settlements in Rural Areas of Japanese Biosphere Reserves; Case of Shiramine Village in Mount Hakusan Biosphere Reserve. Journal of Education and Cultural Studies, 3(1) Online Access.

Root, E., \& Ngampornchai, A. (2013). "I Came Back as a New Human Being" student descriptions of intercultural competence acquired through education abroad experiences. Journal of Studies in International Education, 17(5), 513-532. 
Roysircar, G., \& Gilla, P. A. (2010). Cultural encapsulation and decapsulation of therapist trainees. Culture and the therapeutic process: A guide for mental health professionals, 157-180.

Spitzberg, B., \& Chagnon, G. (2009). Conceptualizing intercultural competence. In D. Deardorff (Ed.), The SAGE handbook of intercultural competence (pp. 2-53). Thousand Oaks, CA: SAGE.

Sue, D. W., \& Sue, D. (2012). Counseling the culturally diverse: Theory and practice. John Wiley \& Sons.

Tezuka, K. (2005). Foreign workers in Japan: Reality and challenges. Japan Labor Review, 2(4), 48.

Von Droste, B. (1991). UNESCO's Man and the Biosphere Programme: Two Decades of Sustainable Development. Colo. J. Int'l Envtl. L. \& Pol'y, 2, 295. 